\title{
Happiness and Success: Genes, Families, and the Psychological Effects of Socioeconomic Position and Social Support ${ }^{1}$
}

\author{
Jason Schnittker \\ University of Pennsylvania
}

\begin{abstract}
Although there is considerable evidence linking success_-including wealth, marriage, and friendships-to happiness, this relationship might not reflect, as is often assumed, the effects of the proximate environment on well-being. Such an interpretation is contravened by evidence that both happiness and the environment are influenced by genetic factors and family upbringing. Using the National Survey of Midlife Development in the United States, which includes a subsample of twins, this study evaluates the relationship between happiness and various features of success before and after eliminating the influence of endowments. The results suggest that many putative indicators of the environment are highly heritable and, indeed, that the same genes that affect the environment may affect happiness as well. Yet the results also suggest that the role of genetic endowments varies considerably across different features of success, suggesting complex patterns of selection, reinforcement, and causation among genes and the environment.
\end{abstract}

Abundant evidence links happiness with the achievements and assets valued by society. Education, work, and income are all associated with greater happiness (Mirowsky and Ross 1986), occupational self-direction is linked to positive affect (Schooler 1984), and social support is among the most powerful predictors of well-being (Smith-Lovin 1995). To explain these relationships, sociologists usually rely on a model wherein the social environment changes psychological states through assorted processes of

\footnotetext{
${ }^{1}$ This article benefited from the comments and suggestions of audiences at the University of Michigan, the University of Chicago, and the University of Pennsylvania. This research was funded, in part, by an NIH grant (1R01 HD046144-01). Direct correspondence to Jason Schnittker, Department of Sociology, University of Pennsylvania, 3718 Locust Walk, Philadelphia, Pennsylvania 19104-6299. E-mail: jschnitt @ssc.upenn.edu

(C) 2008 by The University of Chicago. All rights reserved. 0002-9602/2008/114suppl-0008 $\$ 10.00$
} 
American Journal of Sociology

exposure, learning, and reinforcement. Income, for example, promotes happiness because it allows for consumption and the satisfaction of desire, while support promotes happiness because of the pleasure of interaction and the rewards of social exchange. In addition to being consistent with sociological theory, these pathways are consistent with public perception. Individuals routinely pursue degrees, promotions, and friends, believing that more of each will result in greater happiness. ${ }^{2}$

Yet there is growing evidence that the relationship between happiness and these assorted features of success reflects, in no small part, their codetermination by social or genetic endowments. Taken to an extreme, this idea suggests that once a person reaches adulthood, the environment can do little to influence her well-being, a claim that would seem to cast doubt on much of sociology's accumulated wisdom. Claims along these lines usually begin with the idea that the psychological states sociologists traditionally consider to be outcomes of a social process are in fact highly heritable (see Plomin [1994] for a general review). By the same token, a variety of ostensibly environmental variables, including schooling (Behrman and Taubman 1985), income (Bowles and Gintis 2002), and social support (Kendler 1997), are heritable as well. One might critique the methods these studies use to estimate heritability, but the general conclusion is almost certainly correct-many outcomes of long-standing sociological interest are at least partially heritable, and sociologists should take this fact seriously (see Freese 2008 [in this issue]). Even if not wholly heritable, many outcomes are influenced by factors quite distal from the immediate environment. Along these lines, some argue that early life experiences set in motion trajectories that lead to stable patterns of behavior in adulthood (Collins et al. 2000). From this perspective, no less than from the genetic one, adult well-being should be viewed in light of its childhood origins.

Despite this evidence, most sociologists continue to emphasize the proximate environment and to empirically unravel its many elements. In a review of 30 years of stress research, Turner correctly notes that the question whether the relationship between the social environment and depression reflects selection or causation "does not seem to have been an important concern" in sociology (Turner 2003, p. 2). And he argues, in an appropriately conciliatory fashion, that both are important. Yet Turner belies his modest claim when he goes on to emphasize the role of chronic stress and coping in the relationship between social status and mental

\footnotetext{
${ }^{2}$ Happiness is here defined as the frequency of positive affect. It is by no means the only psychological outcome considered in sociological research on the psychological effects of the social environment. Nevertheless, it remains central and, in other disciplines, has grown increasingly dominant.
} 
health. In his emphasis, he is certainly not alone. Whatever their chosen topic, most sociologists continue to focus on how the environment impinges upon the individual. Likewise, sociologists remain largely unconcerned with the heritability of their assorted outcomes, focusing instead on a strictly social theme. Even among those interested in genetic influence, most focus on interpreting heritability appropriately, rather than examining the implications of heritability for theories of environmental influence (for an exception, see Guo and Stearns 2002). The former enterprise is laudable and informative, but the latter is more promising insofar as it allows sociology to speak to other disciplines in an emerging transdisciplinary dialogue.

In this study, I seek to reevaluate the relationship between success and happiness in light of endowments, and I do so with an eye toward sharpening sociology's theoretical apparatus. I explore a variety of features of success, focusing on those features that have been most central to the discipline, including marital status, schooling, income, and occupational self-direction. For leverage against endowments, I use data consisting of unrelated individuals, ordinary siblings, and identical twins. The analysis is divided into two parts. In the first, I examine whether the same genetic and environmental factors affect both success and happiness, using methods common in behavioral genetics. In the second, I use sibling and twin data to eliminate the influence of endowments. In that context, I use methods familiar to most sociologists in order to provide an analytic bridge with the results from the preceding section.

Given the controversy surrounding genetic research in sociology, some prefatory comments are necessary. Although this study is motivated by evidence of pervasive heritability in environmental and psychological phenotypes, my purpose is not to summarily dismiss the role of the environment in happiness. Nor is it to substantially elevate the role of genes in social processes in the sense that genetic influences are occasionally thought to diminish, of necessity, the relevance of the environment. Rather, my purpose is (1) to suggest that the magnitude of the success-happiness relationship is inflated by genetic influences; (2) to argue that the factors underlying this inflation should be further unpacked, both as a way to properly appreciate environmental influence and as a way to contextualize the influence of genes; and (3) to encourage explanatory pluralism in research on well-being, a position already adopted in fields where behavior genetics has more of a foothold (see Kendler [2005] regarding psychiatry). The effects of genes on the environment are themselves interesting, complex, and worthy of further exploration-and in no way do they foreclose on sociological thinking. Indeed, as I show, the analysis of genes can, among other things, reveal the true complexity of the environment and allow the discipline to say with greater confidence that the environment 
American Journal of Sociology

matters. Furthermore, genetically informed designs allow sociologists to construct more layered causal narratives that highlight, among other things, the importance of social organization, the individual actor, and psychological states.

\section{BACKGROUND}

The relationship between success and happiness can be understood in a variety of ways. At one extreme, the idea of a happiness set point predicts no lasting relationship between success and happiness, because happiness is, instead, a reflection of stable genetic and psychological factors. At the other extreme, the social structure and personality approach predicts that success shapes happiness and that neither genetic factors nor family upbringing can do much to undermine this relationship. In between lies the idea that there is, in fact, a relationship between success and happiness, but one that is biased by endowments in highly particular ways.

\section{Environmental Influences on Happiness}

A core idea in sociology, embodied in the social structure and personality approach, is that social position affects psychological states through assorted processes of exchange, reinforcement, and learning (House 1981). This approach generally argues that the correlation between social position and happiness largely reflects the effects of the former on the latter. Thus, happiness might appear stable in the long term, but only insofar as the environment is itself highly stable. To be sure, there is increasing concern with the idea that individuals actively choose and shape their environment (see McLeod and Lively 2007), but most accounts end with a discussion of how environments "impinge" or "act upon" on the individual. Various features of the environment have been linked to wellbeing.

The case of social support is perhaps the best known. Indeed, the empirical record regarding social support and well-being is unusually broad and consistent (Berkman and Syme 1979; House, Umberson, and Landis 1988). The relationship is usually interpreted in terms of the psychological, behavioral, or material resources that support provides. Support promotes well-being because it leads to positive interactions, a sense of coherence, and the confidence that one will be supported in the future (Antonovsky 1987). Furthermore, support is thought to affect well-being through moderating effects, whereby support minimizes the impact of stress. Consistent with this interpretation, evidence points to the importance of environmental factors in the support-happiness relationship. For 
example, individuals tend to report more happiness when in social situations than when alone, and simply discussing a negative life event tends to reduce its impact (Larson and Csikszentmihalyi 1983). Furthermore, relative to other sources of support, the effects of marriage are especially powerful (Campbell, Converse, and Rodgers 1976), a result thought to reflect the greater reciprocity and stability that marriage usually entails (Waite and Gallagher 2000).

Socioeconomic position is thought to be linked to happiness for similar reasons, but in this case there is generally much greater emphasis on social learning. Occupational self-direction-characterized by discretion and personal responsibility in work-related activities-improves well-being because it entails independent decision making in the context of complex stimuli. Successful performance in such an environment leads in turn to happiness, through a process of generalized learning (Schooler 1984). A similar logic underlies the effects of education and income. Education diminishes negative affect by increasing skills and perceived self-efficacy, which in turn lead to new opportunities and even more efficacy (Mirowsky and Ross 2003). By the same token, income provides the ability to consume goods and pursue desired courses of action, which together improve wellbeing.

The Origins of Continuity in Happiness and the Social Environment

Other approaches, emerging mostly in psychology, are less convinced of a strictly environmental interpretation. Rather than emphasizing environmental influences, these perspectives hypothesize that success and happiness reflect the same underlying factors. Much of this interest reflects the idea of a happiness set point (Lykken and Tellegan 1996; Lykken 1999). The set point refers to the stable level of happiness around which individuals might fluctuate, but to which they will eventually return. As this idea implies, happiness has both stochastic and stable components. Whereas the former are influenced by the proximate environment, including life events and relationships, the latter are determined by a variety of anterior factors, including personality (Lykken and Tellegan 1996). The idea of a set point has been influential, in part because it has received a good deal of support. In a now-classic paper, Brickman, Coates, and Janoff-Bulman (1978) found that neither lottery winners nor accident victims were much affected in the long term by their respective changes in fortune. Some note, however, that the actual results were in fact not nearly as stark as Brickman et al. reported, and, for some events, adaptation is slow or incomplete (see Diener, Lucas, and Scollon 2006). Nevertheless, other studies have found similar patterns for more common life events. The happiness gains associated with marriage, for example, 
American Journal of Sociology

usually last only a few years (Lucas et al. 2003), and most people eventually recover from the death of a spouse (Bonanno, Wortman, and Nesser 2004).

In light of these results, psychologists have pushed their investigations back a step, rather than abandon research on the determinants of happiness altogether. While psychologists now recognize the stability of happiness, the origins of this stability remain in dispute. There are two general approaches. On the one hand, some emphasize genetic influences. The happiness set point perspective, for example, is clear in its emphasis on genes (Lykken and Tellegan 1996). In the same vein, other research points to the heritability of putative environmental measures. For example, there is a strong heritable component to marital status, including the propensity to marry, marital satisfaction, and marital dissolution (McGue and Lykken 1992; Johnson et al. 2004). Likewise, there is a heritable component to work experiences, including work performance, productivity, and occupational interests (Hough and Oswald 2000). In all these cases, personality is thought to be the principal force underlying genetic influence (for a review, see Caspi 2000). For example, genetically based predispositions toward positive and negative mood may result in affiliation and social rejection (Coyne and Whiffen 1995).

On the other hand, some emphasize family effects and socialization. Parenting has been the centerpiece of this approach, but other environmental influences are increasingly prominent. Parental behavior has been linked to a variety of behavioral trajectories (Collins et al. 2000). Among other things, families influence socioeconomic attainment, in part through the development of noncognitive traits and skills (Bowles and Gintis 2002). Recent work has also explored nonfamilial influences on attainment, including peers, schools, and neighborhoods (Sampson, Morenoff, and Gannon-Rowley 2002). Although these approaches usually emphasize socialization over genetics, the implications are much the same-family upbringing imparts the skills necessary for adult attainment.

\section{Mapping the Success-Happiness Relationship}

This literature raises several questions regarding the success-happiness relationship. For instance, it calls into question the quality of evidence used in support of a presumptive causal relationship. In this regard, debates over whether the relationship reflects the immediate environment or an anterior process are not unlike debates over whether childhood outcomes reflect genes or socialization. In this area, genes and socialization remain in conflict precisely because most data are not sufficient to support one claim over another. Given the same results, those who emphasize heritability will see evidence for genetic influence, including evidence that 
parents act in response to their children's genetic proclivities, whereas those who emphasize socialization will see evidence that certain parental behaviors are correlated with adult outcomes and will assume that these correlations cannot be due entirely to the effects of a child's genes on the practices of his or her parents. It is only with the advent of genetically sensitive designs that scholars have been able to derive empirically defensible answers (see Caspi, Roberts, and Shiner 2005 for a review). And the same applies to research on the success-happiness relationship. In the absence of genetically informed research, it is impossible to discern the true impact of the environment, since the environment might simply reflect genetic endowments.

This literature also raises questions regarding the pathways linking success and happiness. Here, too, a genetically informed design is useful. Some features of success may be more vulnerable to endowments than others, and these particularities provide clues regarding the underlying process. If, for example, education instills learned effectiveness, as some argue, then the effects of education should be robust to the influence of endowments. If, on the other hand, the relationship between happiness and occupational self-direction reflects the selection of individuals into jobs appropriate for their personality, the effects of self-direction should be rather vulnerable to endowments, especially genetic ones. In this case, the same factors that lead to happiness also lead individuals to select jobs they find desirable. Similar distinctions are possible with respect to support. If choices regarding a spouse are more sensitive to genetic phenotypes than choices regarding friends, the effects of marriage should be sensitive to genetic influence. In exploring distinctions of this sort, my concern is not simply understanding whether the relationship between success and happiness is spurious; rather, it is understanding how genetic factors do or do not influence the environment.

\section{Analytic Strategy}

My analysis consists of two parts. The first is an exploration of the genetic and environmental covariance between happiness, socioeconomic position, and social support, which is modeled using a multivariate ACE model (Plomin et al. 2005). This is a structural equation model in which additive genetic (A), common environmental (C), and unique environmental (E) influences are estimated as latent variables. Figure 1 presents the structure of the model. The model is presented for twin pairs, with three phenotypes for each twin. Socioeconomic position, happiness, and social support are denoted as latent variables because their scores reflect assorted indicators, which are described in greater detail below. The contributions of genes and the environment are identified by using a two- 


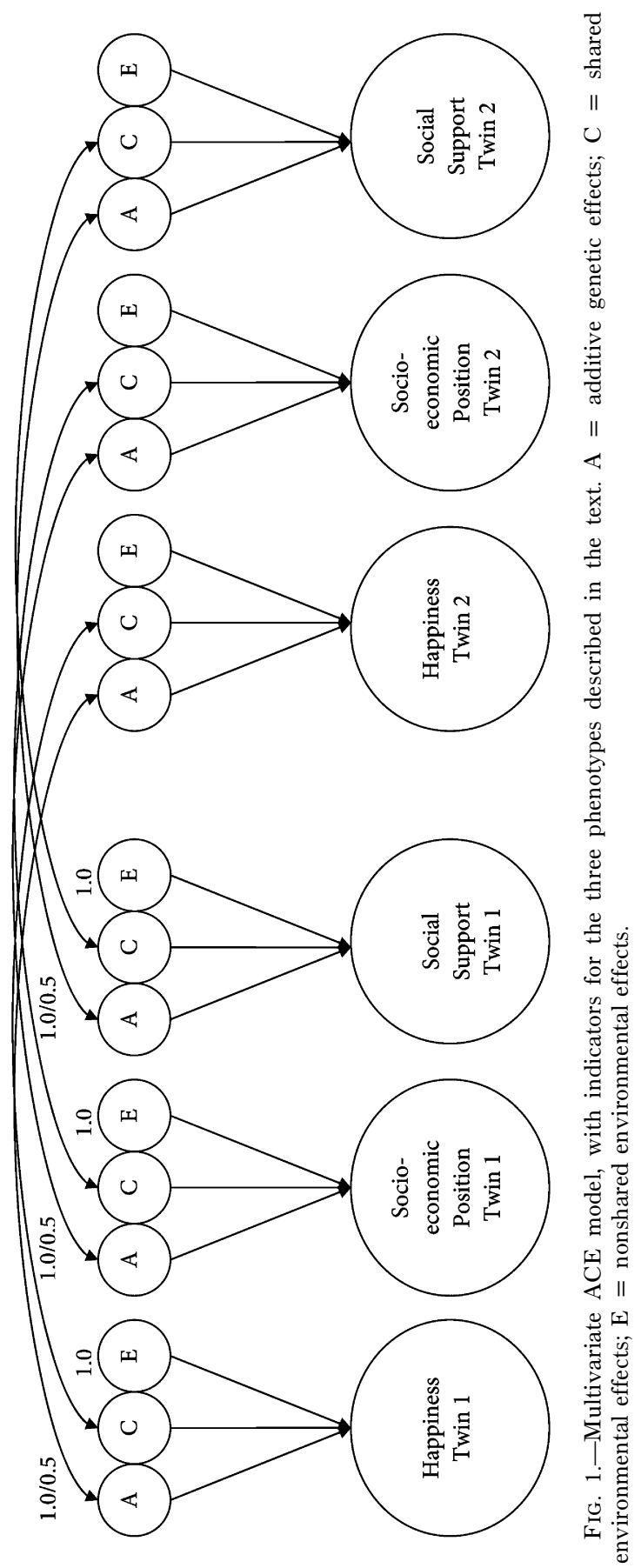


group model and correlating the $\mathrm{A}$ and $\mathrm{C}$ factors at different levels depending on degree of relatedness. Specifically, the A factor is correlated at 1 for monozygotic (MZ) twins and at .5 for dizygotic (DZ) twins. The $\mathrm{C}$ factor, meanwhile, is correlated at 1 for both $\mathrm{MZ}$ and DZ twins, as the siblings in this study are raised in the same household.

The multivariate ACE model is especially useful for this study. Conventional heritability calculations neglect covariance among phenotypes, and, as shown in the figure, each of the three phenotypes has its own A, $\mathrm{C}$, and $\mathrm{E}$ components. However, by imposing theoretically motivated constraints and evaluating relative model fit, it is possible to determine whether the same genetic and environmental factors underlie multiple phenotypes. To this end, equality constraints will be imposed on the A and $\mathrm{C}$ factors, and the best-fitting model will be used to calculate heritabilities, environmentalities, and specificities. By shedding light on the potentially common genetic and environmental factors underlying disparate phenotypes, the ACE model provides information on the precise structure of endowments, not simply on whether they exist.

The second part of the analysis is an exploration of how endowments affect inferences. Ordinary regression analyses performed on samples of unrelated persons are more common than ACE models (but see Nielsen 2006). But they are usually incomplete: they often fail to account for all potential social endowments, and of course, they rarely include any allowance for genetic influences. In the second part of the analysis, I estimate a series of models that regress happiness on assorted features of success. Three models are presented for each feature. The first model explores the success-happiness relationship in a sample of unrelated individuals, which provides a baseline for comparison. The second explores the relationship in a sample of ordinary siblings. By using family fixed effects on this sample, this model partially eliminates the influence of endowments. Finally, the third model explores the success-happiness relationship in a sample of monozygotic twins. This model also uses family fixed effects, but, in the case, fixed effects eliminate social and genetic endowments entirely.

For illustration, consider the following equation, where $i$ indexes individuals and $j$ indexes sibling pairs (for a similar illustration, see Kohler, Behrman, and Skytthe 2005). Assume that sample consists of both monozygotic twins and ordinary siblings:

$$
\text { Happiness } \left._{i j}=\beta_{0}+\beta_{1} \text { (income) }+\beta_{2} \text { (age }\right)+\mu_{j}+\varepsilon_{i j} \text {. }
$$

The term $\mu_{j}$ represents all unobserved endowments that are common to sibling pairs. The nature of these endowments varies between sibling types. In the case of ordinary siblings, the term includes family upbringing and approximately half of the total possible genetic influence. In the case 
American Journal of Sociology

of MZ twins, however, the term includes family upbringing and all genetic factors.

The $\mu_{j}$ term is crucial for estimating the influence of income. If the endowments this term captures are correlated with both the left- and right-side variables, $\beta_{1}$ will be biased. In this example, the bias is perhaps upward, given that the same endowments that influence happiness presumably also influence income, although the direction of the bias is an empirical matter. With conventional household survey data, it is impossible to identify this term. Using sibling and twin pairs, however, one can eliminate $\mu_{j}$ by exploiting within-pair differences. In the case of MZ twins, the above equation reduces after differencing to the following:

$$
\Delta \text { Happiness }_{j}=\beta_{1}(\Delta \text { income })+\Delta \varepsilon_{j} .
$$

Because within-MZ estimates capture all genetic influences, the withinMZ estimator provides a more rigorous test of a relationship.

\section{DATA}

Data come from the National Survey of Midlife Development in the United States (MIDUS) (Brim et al. 2007). The survey contains three parts: a main sample of unrelated persons, a sibling sample, and a twin sample. The main sample was a nationally representative sample of noninstitutionalized, English-speaking adults, ages 25-74, conducted in 1995 and 1996. Phone and mail instruments were administered separately, but this study focuses on respondents who completed both.

Siblings were identified from members of the main sample. A random subset of siblings was selected from those reporting one or more siblings from the same biological parents. Among the families selected, an attempt was made to interview all biological siblings. Twins were identified in a similar fashion, albeit with an expanded scope. Twin pairs were identified either within the national sample directly (i.e., they were respondents in the main sample) or within main-sample respondents' immediate families. About $2 \%$ of main-sample respondents were themselves twins, and $13 \%$ had a twin in their immediate family. Twins were asked a series of questions designed to evaluate their zygosity, including questions regarding shared physical characteristics. Although apparent similarity is by no means a perfect indicator of zygosity, studies reveal a rather high level of concordance between indicators drawn from appearance-based reports and those drawn from more sophisticated molecular tests (Chen et al. 1999). After twin pairs with incomplete information were eliminated, the final sample consisted of 3,023 unrelated persons, 1,366 siblings (including some already counted in the national sample), and 1,588 twins, of whom 
954 were DZ and $634 \mathrm{MZ}$. In the analyses that follow, DZ twins are treated as "ordinary" siblings, resulting in a total sibling sample of 2,330. Controls for age are included to account for age differences between nontwin ordinary siblings.

\section{Variables}

The appendix presents constituent items and coefficient reliabilities for the summary scales. The six items used to measure what I will refer to as happiness reflect positive affect. These items were selected specifically for the MIDUS based on items used in a variety of previously validated instruments. They were not intended to be part of a larger scale. Although these items reflect varying degrees of positive affect, ranging from "calm and peaceful" to "extremely happy" feelings, their correlations are unusually high: the coefficient reliability is just over .9. A summary scale was created using the mean response to these items. This summary scale is more sophisticated than single-item indicators of overall happiness or satisfaction (e.g., "In general, how satisfied are you with your life as a whole?"), but it is nevertheless highly correlated with such measures, allowing for comparability with other studies. Some additional comments are necessary. First, this measure asks about happiness over a definite and short time period (30 days). Although averaging repeated measures over a longer time period could provide a more accurate gauge of a set point, point-in-time measures are correlated with measures taken over a longer time frame, as one would expect. Moreover, current measures of happiness are more strongly correlated with current measures of socioeconomic position-judgments of global happiness are based on information that is most accessible at that point in time, which, in turn, is related to recency (see Schwarz and Strack [2003] for a review of judgment processes in the measurement of well-being). Second, this measure of happiness should be distinguished from related concepts. Happiness is not the converse of depression, which reflects the frequency of negative affect. Nor is it a purely cognitive weighting of what is with what should $b e$, as might be the case with satisfaction. Happiness is here defined as the experience of frequent positive affect. Thus, the results cannot be applied directly to outcomes that appear, on their face, similar. It is possible, for example, that someone can be satisfied with her marriage even if, in the last 30 days, that marriage provides her with no additional happiness. Yet the results do speak to happiness as it is conventionally defined.

Three key features of success are explored. First, I examine schooling, employment status, personal earnings, and net positive wealth. Schooling is measured in years, personal earnings as log dollars earned from current 
American Journal of Sociology

employment, and wealth as log dollars of total net-positive family wealth. Because these items were observed for every individual, they constitute the indicators of socioeconomic position, as used in the ACE model. To be sure, combining these items into a single latent scale entails some loss of precision. Nevertheless, it provides a general overview that is helpful before moving to the more granular regression results. Second, I explore occupational direction, control, and planning $(D C P)$, also evaluated using a summary scale. This measure reflects the skill and discretion respondents exercising in their usual job, with higher values reflecting more control. Third, I explore social support. I use four specific indicators, reflecting three sources: friend support, (nonspousal) family support, marital status (currently married or not), and spouse support. With the exception of marital status, these indicators are summary scales of perceived relationship content (House et al. 1988). The latent variable for social support used in the ACE model comprises these indicators minus spouse support, which was, of course, observed only among married respondents.

\section{RESULTS}

Table 1 presents basic descriptive statistics. Among the quantities presented are correlations from MZ and same-sex DZ pairs. Twice the difference between these quantities is a simple estimate of narrow-sense heritability. Heritability refers to the contribution of genetics to variance in a phenotype in a particular population at a particular time and place; it does not refer to the fixed phenotype of an individual (Plomin et al. 2005). As the literature discussed above anticipates, the heritability for most of the variables is quite high. The heritability of happiness is just under $45 \%$. Some features of success show even higher heritability. For example, the heritability of spouse support is just under $60 \%$, and even marital status shows heritability over $50 \%$. Although these estimates might, on their face, appear large, most of them are consistent with previous research. Indeed, if anything, some of the estimates are smaller than those found elsewhere. For example, some studies report that the heritability of schooling is just over 80\% (Behrman and Taubman 1989). Similarly, some studies report that the heritability of social support varies from just over $40 \%$ to around $70 \%$, depending on model assumptions (Kendler 1997). While there is considerable variation between the variables, the fact that they all share at least moderate heritability suggests a potentially powerful role of genes.

The next two tables turn to the ACE model. Basic fit statistics for nine models are presented in table 2. The nine models reflect assorted parameter constraints. Model 1 is the most unconstrained model: each of the 
Happiness and Success

TABLE 1

DesCriPtive Statistics ANd HeRITABILITy For Key VARIAbles: 1995-96 MIDUS

\begin{tabular}{|c|c|c|c|c|c|}
\hline Variable & Mean & Range & $r_{\mathrm{DZ}}$ & $r_{\mathrm{MZ}}$ & $h^{2 *}$ \\
\hline Happiness & 3.40 & $1-5$ & .21 & .43 & .44 \\
\hline \multicolumn{6}{|l|}{ Socioeconomic position: } \\
\hline Schooling (years) ..... & 13.73 & $2-20$ & .57 & .70 & .26 \\
\hline Employment & .72 & 0,1 & .32 & .38 & .11 \\
\hline Personal earnings (in 10,000s) & 8.35 & $0-12.5$ & .26 & .40 & .27 \\
\hline ln wealth $\ldots \ldots \ldots \ldots \ldots \ldots \ldots$ & 7.30 & $0-14.22$ & .29 & .37 & .15 \\
\hline $\mathrm{DCP}^{* *} \ldots \ldots \ldots \ldots$ & 3.70 & $1-5$ & .23 & .33 & .21 \\
\hline \multicolumn{6}{|l|}{ Social support: } \\
\hline Friend support $\ldots$ & 3.15 & $1-4$ & .12 & .25 & .26 \\
\hline Family support .... & 3.17 & $1-4$ & .28 & .39 & .22 \\
\hline Married $\ldots \ldots \ldots \ldots \ldots \ldots \ldots \ldots \ldots$ & .74 & 0,1 & -.01 & .25 & .52 \\
\hline Spouse support $\ldots \ldots \ldots \ldots \ldots \ldots \ldots$ & 3.18 & $1-4$ & .01 & .30 & .59 \\
\hline
\end{tabular}

$* h^{2}=2\left(r_{\mathrm{MZ}}-r_{\mathrm{DZ}}\right)$.

** DCP $=$ occupational direction, control, and planning.

three phenotypes has its own A, C, and E factor. Models 2 and 3 impose pairwise constraints on the A factors. Models 4 and 5 impose parallel pairwise constraints on the $\mathrm{C}$ factors. Models 6 and 7 assume that the same $\mathrm{A}$ and $\mathrm{C}$ factors affect all three phenotypes, while model 8 imposes equality constraints on both the $\mathrm{A}$ and $\mathrm{C}$ factors simultaneously. Model 9 assumes no genetic influence.

The best-fitting model (6) is one in which each phenotype is influenced by the same genetic factor, but has a unique environmentality. This result does not mean that each factor has precisely the same heritability, but it does suggest that the same genetic factors influence all three phenotypes. Two other models are revealing for different reasons. Model 7, where the three $\mathrm{C}$ factors are constrained to be equal, yields a poor fit, as does model 9, where all three A factors are assumed to be zero. Genetic influences cannot be ignored.

Table 3 presents estimated values for $h^{2}, c^{2}$, and $e^{2}$ implied by model 6 , the best-fitting model in table 2 . For comparison, the table also presents values implied by model 1 . Both models reveal that common environmentalities have little influence on happiness. Indeed, model 1 estimates the value of $c^{2}$ at zero, a result consistent with estimates from other studies of well-being (Nes et al. 2006). Common environmentalities play much more of a role in socioeconomic position and social support. For each of the three phenotypes, the single largest influence-by far, in some casescomes from unique environmentalities. To be sure, E includes measurement error. Nevertheless, these estimates suggest that the predominant 


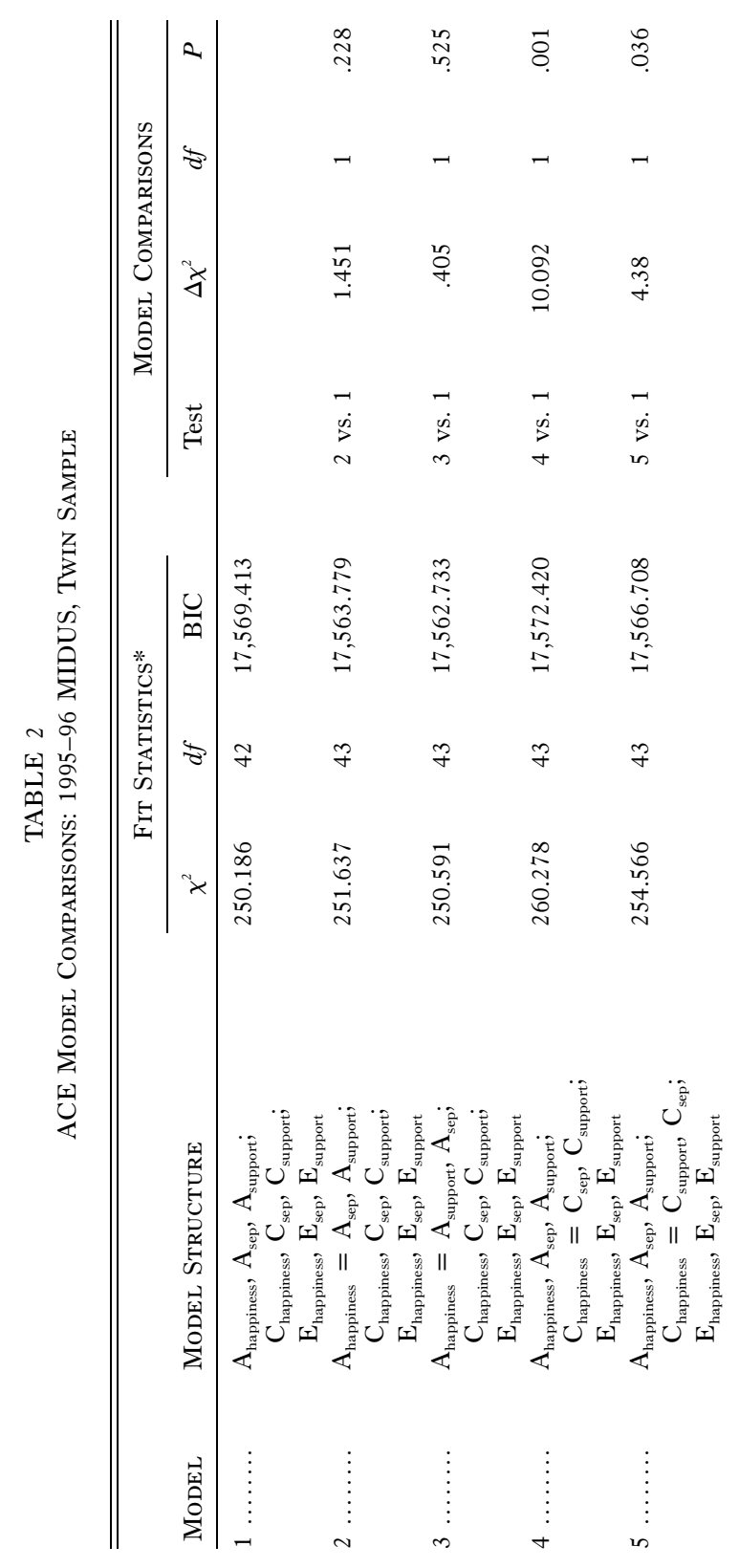




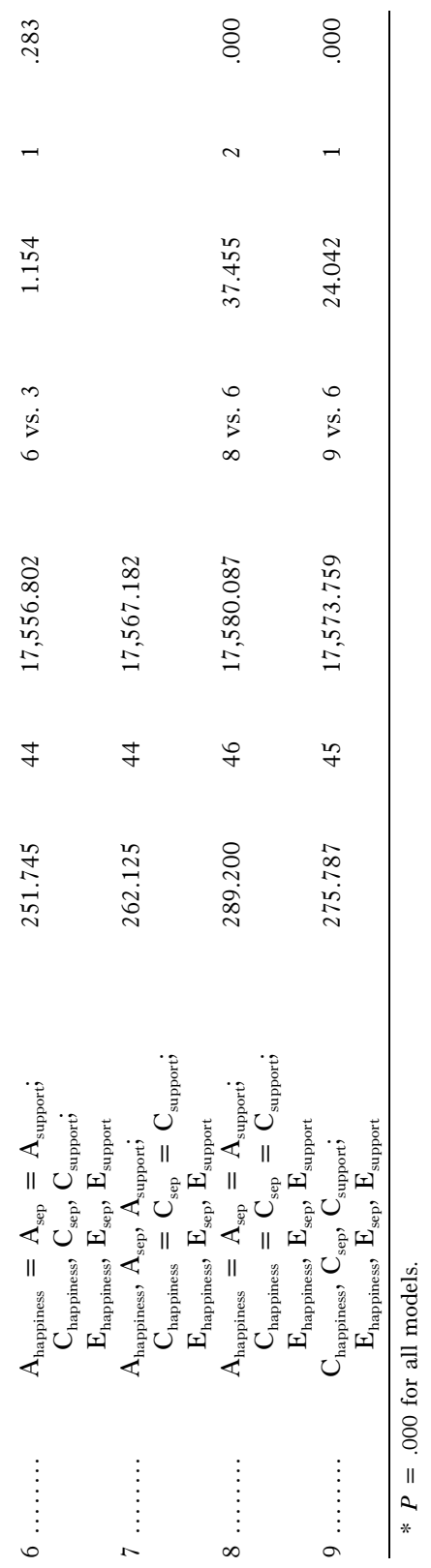


American Journal of Sociology

TABLE 3

Heritabilities, Environmentalities, and Specificities from

Unconstrained and Favored Models: 1995-96 MIDUS, Twin

SAMPLE

\begin{tabular}{|c|c|c|c|}
\hline & $h^{2}$ & $c^{2}$ & $e^{2}$ \\
\hline \multicolumn{4}{|l|}{ Model 1: } \\
\hline Happiness $\ldots . \ldots \ldots \ldots \ldots$ & $.433(.029)$ & $.000(.000)$ & $.567(.029)$ \\
\hline Socioeconomic position .... & $.144(.090)$ & $.295(.075)$ & $.561(.031)$ \\
\hline Social support $\ldots \ldots \ldots \ldots \ldots$ & $.169(.098)$ & $.202(.081)$ & $.629(.033)$ \\
\hline \multicolumn{4}{|l|}{ Model 6: } \\
\hline Happiness $\ldots \ldots \ldots \ldots \ldots$ & $.363(.074)$ & $.055(.066)$ & $.582(.029)$ \\
\hline Socioeconomic position .... & $.227(.047)$ & $.230(.045)$ & $.544(.025)$ \\
\hline Social support $\ldots \ldots \ldots \ldots \ldots$ & $.199(.041)$ & $.178(.042)$ & $.623(.027)$ \\
\hline
\end{tabular}

NoTE.-Numbers in parentheses are SEs.

source of environmental influence reflects factors that produce withinfamily differences rather than within-family similarities.

The next three tables turn to the regression models. Three models are presented for each feature of success, as discussed above. Table 4 begins with socioeconomic position. The results are remarkably consistent for each of the four features of success. In model 1, without considering anything family members have in common, schooling, employment, income, and wealth are positively associated with happiness, as expected.

However, the next two models reveal a different story. When withinsiblings estimation is used, all but one of the coefficients is reduced to statistical insignificance. Moreover, the absolute magnitude of the reduction is striking. In most cases, the coefficient is diminished by well over $50 \%$, and indeed, in the case of schooling, the coefficient reverses direction (but is insignificant). Most of the total reduction occurs within ordinary siblings, suggesting that genetic endowments play less of a role than social endowments.

Table 5 turns to job characteristics. As in table 4, model 1 reveals a strong association, this time between DCP and happiness. However, in contrast to the effects of other features of socioeconomic position, the effects of DCP are remarkably robust. The coefficient from the withinsiblings model is almost identical to that from the sample of unrelated persons. The coefficient from the within-MZ-twins model is reduced by a mere $10 \%$. Although genetic endowments are the key confounding factor for DCP, their influence is negligible. This is perhaps a surprising result, given the presumptive role of personality in matching individuals with jobs, but hardly surprising through the lens of social structure and personality. 
Happiness and Success

TABLE 4

Socioeconomic Position ANd Happiness: 1995-96 MIDUS

\begin{tabular}{lccc}
\hline \hline & $\begin{array}{c}\text { Between } \\
\text { Unrelated Persons } \\
(1)\end{array}$ & $\begin{array}{c}\text { Within } \\
\text { Ordinary Siblings } \\
(2)\end{array}$ & $\begin{array}{c}\text { Within } \\
\text { MZ Twins } \\
(3)\end{array}$ \\
\hline Schooling (in years) $\ldots$ & $.014^{*}$ & -.003 & -.009 \\
& $(.005)$ & $(.009)$ & $(.023)$ \\
Employment .......... & $.148^{*}$ & .063 & .033 \\
& $(.032)$ & $(.046)$ & $(.091)$ \\
Income (in 10,000s) $\ldots$. & $.018^{*}$ & .002 & .009 \\
& $(.004)$ & $(.005)$ & $(.011)$ \\
ln wealth ............ & $.013^{*}$ & $.019^{*}$ & .004 \\
& $(.003)$ & $(.004)$ & $(.007)$ \\
No. observations ....... & 3,023 & 2,330 & 634 \\
No. families .......... & & 986 & 317 \\
\hline
\end{tabular}

NotE. - Numbers in parentheses are SEs. Models 1 and 2 also control for age and age ${ }^{2}$.

$* P<.01$.

TABLE 5

Occupational Direction, Control, and Planning (DCP) and Happiness, EMPLOYED RESPONDENTS: 1995-96 MIDUS

\begin{tabular}{lccc}
\hline \hline & $\begin{array}{c}\text { Between } \\
\text { Unrelated Persons } \\
(1)\end{array}$ & $\begin{array}{c}\text { Within } \\
\text { Ordinary Siblings } \\
(2)\end{array}$ & $\begin{array}{c}\text { Within } \\
\text { MZ Twins } \\
(3)\end{array}$ \\
\hline DCP .............. & $.153^{* *}$ & $.155^{* *}$ & $.138^{*}$ \\
& $(.020)$ & $(.033)$ & $(.063)$ \\
No. observations ... & 2,124 & 1,660 & 488 \\
No. families ....... & & 864 & 279 \\
\hline
\end{tabular}

NotE. - Numbers in parentheses are SEs. Models 1 and 2 also control for age and age ${ }^{2}$. $* P<.05$.

** $P<.01$

Table 6 turns to social support. Here, too, the coefficients for support are generally robust to genetic endowments, but the patterns vary considerably between sources. The support of friends and family is strongly related to happiness. Moreover, genetic endowments do little to eliminate this association. The coefficient for friend support, for example, is reduced by $13 \%$ between models 1 and 3 . The coefficient for family support is reduced by $43 \%$, but remains significant. Overall, social endowments play little role. Indeed, if anything, social endowments suppress the supporthappiness relationship, suggesting, as with schooling, that endowments have divergent and complex effects. For both friend and family support, the coefficient observed in model 2 is larger than that in model 1.

Yet this is not a general pattern; the patterns for marriage are very different. The relationship between marital status and happiness, while 
American Journal of Sociology

TABLE 6

SOCIAL SUPPORT AND HAPPINESS: 1995-96 MIDUS

\begin{tabular}{cccc}
\hline \hline & $\begin{array}{c}\text { Between } \\
\text { Unrelated Persons } \\
\end{array}$ & $\begin{array}{c}\text { Within } \\
\text { Ordinary Siblings } \\
(1)\end{array}$ & $\begin{array}{c}\text { Within } \\
\text { MZ Twins } \\
(3)\end{array}$ \\
\hline All but spouse support: & & & \\
Friend support ..... & $.374^{*}$ & $.480^{*}$ & $.325^{*}$ \\
& $(.029)$ & $(.041)$ & $(.073)$ \\
Family support ..... & $.409^{*}$ & $.477^{*}$ & $.233^{*}$ \\
& $(.026)$ & $(.040)$ & $(.073)$ \\
Married .......... & $.120^{*}$ & $.225^{*}$ & .076 \\
& $(.029)$ & $(.045)$ & $(.086)$ \\
No. observations .... & 3,023 & 2,330 & 634 \\
No. families ........ & & 986 & 317 \\
Spouse support ....... & $.429^{*}$ & $.393^{*}$ & $.133^{+}$ \\
& $(.027)$ & $(.041)$ & $(.080)$ \\
No. observations .... & 2,110 & 1,829 & 505 \\
No. families ........ & & 941 & 291 \\
\hline
\end{tabular}

Note. - Numbers in parentheses are SEs. Models 1 and 2 also control for age and age ${ }^{2}$.

$+P<.10$.

$* P<.01$.

elevated when using within-siblings estimation, is reduced to insignificance when using within-MZ-twins estimation. Even the more contextual and qualitative measure of spouse support is vulnerable to genetic influence. For example, the effects of spouse support on happiness are reduced by $69 \%$ in model 3 , and the coefficient is significant only at $P<.10$. Considering the results for all three sources of support together, it appears that the closer a relationship is to family, the more it is subject to genetic influence.

\section{DISCUSSION}

In pursuit of a theoretical framework sensitive to endowments, this study employed a sibling and twin design and compared models that exploit family-based information with those that do not. At a basic level, the results reveal the rather considerable impact of endowments. The ACE model indicates that happiness is highly heritable and, moreover, that the same genes that affect happiness also affect socioeconomic position and social support. Because of this shared phenotypic structure, the influence of many features of success is diminished to statistical insignificance once endowments are considered. This is the case even for some of the most emphasized features in the literature. For example, the effects of schooling, usually presumed to be self-amplifying and rooted in learning (Mirowsky 
and Ross 2003), disappear once social endowments are considered. Likewise, the effects of marriage, often considered the single most important contributor to well-being (Campbell et al. 1976), are reduced to statistical insignificance once genes are considered.

Interpreted only in terms of how consistently these assorted relationships are diminished, the results would seem to support the idea of a set point: they reveal that there are robust anterior forces rooted in genes and family upbringing that systematically push happiness toward dispositional levels. Yet the results also suggest greater variability in the set point than is usually implied and, thus, suggest some level of agency (see also Diener et al. [2006] on this point). Recall that one of the more controversial claims of the set-point literature is that individuals can do little to permanently alter their psychological well-being. According to this interpretation, improvements in happiness are merely short-term perturbations from a more essential set point, and only change in the environment can improve happiness. In keeping with this interpretation, it is useful to consider why some particular measures are less sensitive to adaptation than others.

For most people, support from family and friends has lasting effects on well-being. Similarly, the relationship between happiness and DCP is not greatly affected by genes. It is possible that these measures reflect aspects of the environment that are not readily subject to adaptation. If, as the set-point theory predicts, change in the environment is the key to happiness, the most important features of success should be those that entail novelty. Thus, the effects of occupational control might derive from the fact that occupational control, in addition to capturing some enduring features of social position, captures the possibility of variety. By the same token, measures of friend support might have stronger effects than measures of spouse support if the former entails more novelty. If this line of thinking is correct, the treadmill metaphor is appropriate-individuals do respond to changes in the environment rather than levels-but applied too generally. In particular, the metaphor fails to convey how certain features of socioeconomic position, as well as certain kinds of relationships, lead to lasting improvements through flexibility, regular stimulation, and so on. In short, some features of the environment create structured opportunities for spontaneity, not simply structured patterns of behavior.

This may also explain why some features of success are especially sensitive to genetic influence. In this regard, the results regarding social support are perhaps the most intriguing. The results reveal that the ordering of social support, from most powerful to least, reverses direction once genes are considered, owing to the fact that genetic endowments matter more for an individual's spouse than for her friends. Indeed, there is a considerable discontinuity between the two-genes hardly matter at all 
American Journal of Sociology

with respect to the happiness derived from friends, but they matter a great deal with respect to the happiness derived from family. One interpretation of this finding is that a successful family life requires a set of more or less stable characteristics, such as mutual attraction, complementary personalities, and repeated cooperation, whereas a successful friendship allows for more elasticity. At the same time, this finding speaks to phenotypic assortment between different dimensions of support. Recent reviews of mate selection suggest that assortative mating occurs along many heritable dimensions, including personality, physical attractiveness, and cognitive ability (Caspi and Herbener 1990). To the extent that these dimensions are also correlated with happiness, assortative mating will inflate the impact of genes and lead, in turn, to endowment-sensitive associations between marriage and happiness. Choices among friends, by contrast, might be less sensitive to genes, given their multiplicity and breadth. Because friendships ordinarily entail less commitment and routine, they can develop through dynamic choice and coincidence, and such factors might be critical to lasting improvements in happiness. At a more basic level, indicators based on a particular individual (e.g., a spouse) might be more vulnerable to endowments than indicators based on generic categories (e.g., friends) precisely because the latter is indefinite and ordinarily entails more than one person.

The results speak to sociology's theoretical enterprise in other ways as well. They suggest that, for many questions, the pursuit of specific environmentalities might be more generative than the pursuit of specific genes. This, too, cuts against the grain. Recall that the best-fitting ACE model reveals that the same genetic structure underlies all three phenotypes, but the environmentalities influencing these phenotypes are unique. Although scholars regularly note the small and poorly understood role of common environmentalities in individual differences, behavioral genetics has increasingly pushed research toward identifying specific genes and polymorphisms underlying specific phenotypes. Such efforts, while leading to some of the most exciting research programs in contemporary social science (e.g., Caspi et al. 2003), should not overshadow further drilling down with respect to the environment. If anything, the effects of the environment may be more complex than those of genes, in that they are more phenotype-specific. Thus, individuals may glean specific competencies from certain features of their environment, even as they gain a more general edge from their genes. Much of sociology's current thinking is not at this level of granularity, instead reflecting an interest in coarser concepts, like socioeconomic attainment. By the same token, sociology will benefit from expanding the scope of its investigations, especially in the direction of considering multiple environments simultaneously. In focusing to a large extent on family effects, sociologists may have overlooked the 
many environments siblings do not share, a point many sociologists have recognized already but have not vigorously tried to address.

A more general point is that the serious consideration of genes hardly undermines the relevance of sociology and, indeed, might allow sociologists to address the kinds of action/structure questions that have long animated the discipline. To be sure, current research on social structure and personality has explored how individuals select themselves into environments in ways that promote or hinder their well-being (see McLeod and Lively 2007). Yet, even when demonstrating the importance of selection, sociologists have generally shown little appreciation of the origins of this action or the strategy it reflects. Genes are useful in this regard in that they provide a mechanism for understanding how individuals respond to and shape their environment, and, as demonstrated here, investigating genes hardly obviates the importance of the environment. Among potential engines of action reflected in genes are personality, tolerance of risk, cognitive abilities, and time preferences (see Freese 2008).

\section{Limitations}

This study has at least three limitations. First, many of the measures are based on self-report, which leads to some interpretive ambiguity. For example, it is impossible to determine whether endowments affect how individuals attract social support or how individuals interpret supportive exchange, an important distinction for understanding how genes are expressed in the environment. The variables do, however, provide some leverage in this regard: the data include both dimensional indicators of relationship content and categorical identifiers, such as married or not. If reports of support were only a matter of perception (e.g., because dispositionally happy people see the best in everyone), we would expect much higher heritability among the dimensional variables than among the categorical ones. The heritability of spouse support does in fact exceed that of marital status, but the difference is quite small. Furthermore, there is considerable heterogeneity among the heritabilities of the dimensional measures. For example, the heritability of perceived spouse support exceeds that of friend and family support, suggesting either that the cognitive aspects of support vary from domain to domain or that some objective features of support were in fact measured.

Second, while this study estimated the impact of endowments, it did not identify the process that makes these endowments relevant. To say, for example, that the effects of support are biased unless endowments are considered reveals little about how endowments influence support. This, too, is an opportunity for sociology's input, as the influence of nature depends highly on what a society chooses to value and reward. This study 


\section{American Journal of Sociology}

also exploits differences between twins, but cannot pinpoint the reasons for these differences. The twin design is often considered a natural experiment, but clearly monozygotic twins do not receive different levels of, say, schooling for reasons that are entirely random. Furthermore, the specific factors that lead to twin differences in schooling might be implicated in happiness as well.

Finally, several limitations emerge from the twin design itself. The twin design assumes that $\mathrm{MZ}$ and $\mathrm{DZ}$ twins experience the same environmentally caused similarity; this is referred to as the equal environments assumption (EEA). However, MZ twins may be treated more similarly than DZ twins, and violations of the EEA could, in principle, inflate estimates of heritability. The EEA has been tested for a variety of traits, and its violation seems not to radically alter estimates of heritability or to make estimates derived from twin studies drastically different from those derived from other designs (Borkenau et al. 2002; Bouchard and McGue 2003). At the same time, not all assumptions work to inflate the apparent relevance of genes; some assumptions of the twins approach (e.g., no assortative mating) underestimate heritability (Plomin et al. 2005). Future research should be mindful of the EEA, but it seems unlikely that its violation is especially pervasive or problematic. Moreover, in the literature's present state, questioning the empirical accuracy of heritability may be less fruitful than seriously engaging twin research and exploiting its methods. Estimates of heritability are sensitive to more than assumptions regarding covariance, and these sensitivities might, in the end, provide sociologists with an opportunity for theory and research. It is worth reiterating that my estimates are, like any such estimates, context-specific, and there are reasons to expect that some genes may be especially relevant at the present moment. In particular, there may be more active phenotypic assortment in the marriage and labor markets now than there has been in the past. For example, if mate selection is increasingly independent of local marriage markets, the impact of genes on marriage could be increasing. Similarly, if employees are increasingly free of close supervision, genes could be more important insofar as employers are inclined to hire workers whose disposition inspires confidence. The important point is that each of these possibilities is an opportunity for further investigation and theory building, not an intractable empirical limitation bound only to render estimates of heritability meaningless.

\section{Conclusion}

In a narrow sense, this study was concerned with the effects of success on happiness in light of endowments. In a broad sense, however, the goal was to encourage sociologists' further engagement with the genetic bases 
of behavior and the more widespread adoption of methods suitable for addressing genetic influence. To this end, it is important to remember that genes and the environment are not pitted against each other in a zerosum contest, but operate in concert. Thus, understanding the mechanisms whereby social position affects psychological states requires understanding the ways in which genes influence exposure to the environment (see Dawkins 1982). And, by the same token, understanding how genes affect psychological states requires serious attention to social processes. Above all, the results of this study hint at the benefits of coordinated efforts, including the importation of methods ordinarily used in behavioral genetics as well as the exportation of some of the concepts motivating social structure and personality. The end result of more genetically informed research will be theories that are more complete, complex, and resonant across disciplines.

\section{APPENDIX}

Scale Items and Reliability: 1995-96 MIDUS

Happiness $(\alpha=.91)$ :

During the past 30 days, how much of the time did you feel:

cheerful?

in good spirits?

extremely happy?

calm and peaceful?

satisfied?

full of life?

Response categories: all of the time, most of the time, some of the time, a little of the time, none of the time

Direction, control, and planning $(\alpha=.86)$ :

How often does your work demand a high level of skill or expertise?

How often do you have to initiate things?

How often do you have a choice in deciding how you do your tasks at work?

How often do you have a choice in deciding what tasks you do at work?

How often do you have a say in decisions about your work?

How often do you have a say in planning your work environment?

How often does your job provide you with a variety of things that interest you?

Response categories: all of the time, most of the time, sometimes, rarely, never 


\section{American Journal of Sociology}

Friend/family support ( $\alpha=.79$ for friend support; $\alpha=.83$ for family support):

How much do your friends/family (not including your spouse/partner or those living with you) really care about you?

How much do they understand the way you feel about things?

How much can you rely on them for help if you have a serious problem?

How much can you open up to them if you need to talk about your worries?

How often do your friends make too many demands on you?

How often do they criticize you?

How often do they let you down when you are counting on them?

How often do they get on your nerves?

Response categories: a lot, some, a little, not at all

Spouse support $(\alpha=.92)$ :

How much does your spouse or partner really care about you?

How much does he or she understand the way you really feel about things?

How much does he or she appreciate you?

How much can you rely on him or her for help if you have a serious problem?

How much can you open up to him or her if you need to talk about your worries?

How much can you relax and be yourself around him or her?

How often does your spouse or partner make too many demands on you?

How often does he or she make you feel tense?

How often does he or she argue with you?

How often does he or she criticize you?

How often does he or she let you down when you are counting on him or her?

How often does he or she get on your nerves?

Response categories: a lot, some, a little, not at all

\section{REFERENCES}

Antonovsky, Aaron. 1987. Unraveling the Mystery of Health: How People Manage Stress and Stay Well. San Francisco: Jossey-Bass.

Behrman, Jere, and Paul Taubman. 1985. "Intergenerational Earnings Mobility in the United States: Some Estimates and a Test of Becker's Intergenerational Endowments Model." Review of Economics and Statistics 67:144-51.

. 1989. "Is Schooling 'Mostly in the Genes'? Nature-Nurture Decomposition Using Data on Relatives." Journal of Political Economy 97:1425-46.

Berkman, Lisa F., and S. Leonard Syme. 1979. "Social Networks, Host Resistance, 


\section{Happiness and Success}

and Mortality: A 9-Year Follow-Up Study of Alameda County Residents." American Journal of Epidemiology 109:186-204.

Bonanno, George A., Camille B. Wortman, and Randolph M. Nesser. 2004. "Prospective Patterns of Resilience and Maladjustment during Widowhood." Psychology and Aging 19:260-71.

Borkenau, Peter, Rainer Riemann, Alois Angleitner, and Frank M. Spinath. 2002. "Similarity of Childhood Experiences and Personality Resemblance in Monozygotic and Dizygotic Twins: A Test of the Equal Environments Assumption." Personality and Individual Differences 33:261-69.

Bouchard, Thomas J., Jr., and Matt McGue. 2003. "Genetic and Environmental Influences on Human Psychological Differences." Journal of Neurobiology 54:4-45.

Bowles, Samuel, and Herbert Gintis. 2002. "The Inheritance of Inequality." Journal of Economic Perspectives 16:3-30.

Brickman, Philip, Dan Coates, and Ronnie Janoff-Bulman. 1978. "Lottery Winners and Accident Victims: Is Happiness Relative?" Journal of Personality and Social Psychology 36:917-27.

Brim, Orville G., Paul B. Baltes, Larry L. Bumpass, et al. 2007. National Survey of Midlife Development in the United States (MIDUS), 1995-1996. (Computer file). ICPSR02760-v4. Produced by DataStat, Ann Arbor, Mich., and Harvard Medical School, Department of Health Care Policy, Boston. Distributed by the Interuniversity Consortium for Political and Social Research, Ann Arbor, Mich.

Campbell, Angus, Philip E. Converse, and Willard L. Rodgers. 1976. The Quality of American Life. New York: Russell Sage Foundation.

Caspi, Avshalom. 2000. "The Child Is the Father of the Man: Personality Continuities from Childhood to Adolescent." Journal of Personality and Social Psychology 78: 158-72.

Caspi, Avshalom, and Ellen S. Herbener. 1990. "Continuity and Change: Assortative Marriage and the Consistency of Personality in Adulthood." Journal of Personality and Social Psychology 58:250-58.

Caspi, Avshalom, Brent W. Roberts, and Rebecca L. Shiner. 2005. "Personality Development, Stability and Change." Annual Review of Psychology 56:453-84.

Caspi, Avshalom, Karen Sugden, Terrie E. Moffitt, et al. 2003. "Influence of Life Stress on Depression: Moderation by a Polymorphism in the 5-HTT Gene." Science 301: 386-89.

Chen, Wei J., Huai-Wen Chang, Mu-Zon Wu, et al. 1999. "Diagnosis of Zygosity by Questionnaire and Polymarker Polymerase Chain Reaction in Young Twins." Behavior Genetics 29:115-23.

Collins, Andrew W., Eleanor E. Maccoby, Laurence Steinberg, E. M. Hetherington, and Marc H. Bornstein. 2000. "Contemporary Research on Parenting: The Case for Nature and Nurture." American Psychologist 55:218-32.

Coyne, James C., and Valerie E. Whiffen. 1995. "Issues in Personality as Diathesis for Depression: The Case of Sociotropy-Dependency and Autonomy-Self-Criticism." Psychological Bulletin 118:358-78.

Dawkins, Richard. 1982. The Extended Phenotype: The Gene as the Unit of Selection. New York: Oxford University Press.

Diener, Ed, Richard E. Lucas, and Christie N. Scollon. 2006. "Beyond the Hedonic Treadmill: Revising the Adaptation Theory of Well-Being." American Psychologist 61:305-14.

Freese, Jeremy. 2008. "Genetics and the Social Science Explanation of Individual Outcomes.” American Journal of Sociology 114 (suppl.): S1-S35.

Guo, Guang, and Elizabeth Stearns. 2002. "The Social Influences on the Realization of Genetic Potential for Intellectual Development." Social Forces 80:881-910.

Hough, Leaetta M., and Frederick L. Oswald. 2000. "Personnel Selection: Looking 


\section{American Journal of Sociology}

toward the Future-Remembering the Past." Annual Review of Psychology 51: 631-64.

House, James S. 1981. "Social Structure and Personality." Pp. 525-61 in Sociological Perspectives on Social Psychology, edited by Morris Rosenberg and Ralph Turner. New York: Basic Books.

House, James S., Deborah Umberson, and Karl R. Landis. 1988. "Structures and Processes of Social Support.” Annual Review of Sociology 14:193-318.

Johnson, Wendy, Matt McGue, Robert F. Krueger, and Thomas J. Bouchard, Jr. 2004. "Marriage and Personality: A Genetic Analysis." Journal of Personality and Social Psychology 86:285-94.

Kendler, Kenneth S. 1997. "Social Support: A Genetic Epidemiologic Analysis." American Journal of Psychiatry 154:1398-1404.

. 2005. "Toward a Philosophical Structure for Psychiatry." American Journal of Psychiatry 162:433-40.

Kohler, Hans-Peter, Jere R. Behrman, and Axel Skytthe. 2005. "Partner + Child = Happiness? The Effects of Partnerships and Fertility on Well-Being." Population and Development Review 31:407-45.

Larson, Reed, and Mihály Csikszentmihalyi. 1983. "The Experience Sampling Method." Pp. 41-56 in Naturalistic Approaches to Studying Social Interaction, edited by Harry T. Reis. San Francisco: Jossey-Bass.

Lucas, Richard E., Andrew E. Clark, Yannis Georgellis, and Ed Diener. 2003. "Reexamining Adaptation and the Set Point Model of Happiness: Reactions to Changes in Marital Status." Journal of Personality and Social Psychology 84:527-39.

Lykken, David T. 1999. Happiness: What Studies on Twins Show Us about Nature, Nurture, and the Happiness Set Point. New York: Golden Books.

Lykken, David T., and Auke Tellegen. 1996. "Happiness Is a Stochastic Phenomenon." Psychological Science 7:186-89.

McGue, Matt, and David T. Lykken. 1992. "Genetic Influence on Risk of Divorce." Psychological Science 3:368-73.

McLeod, Jane D., and Kathryn J. Lively. 2007. "Social Psychology and Stress Research.” Pp. 275-303 in Mental Health, Social Mirror, edited by William R. Avison, Jane D. McLeod, and Bernice A. Pescosolido. New York: Springer Press.

Mirowsky, John, and Catherine E. Ross. 1986. "Social Patterns of Distress." Annual Review of Sociology 12:23-45.

2003. Education, Social Status, and Health. New York: Aldine de Gruyter.

Nes, R. B., E. Roysamb, K. Tambs, J. B. Harris, and T. Reichborn-Kjennerud. 2006. "Subjective Well-Being: Genetic and Environmental Contributions to Stability and Change." Psychological Medicine 36:1-10.

Nielsen, François. 2006. "Achievements and Ascription in Educational Attainment: Genetic and Environmental Influences on Adolescent Schooling." Social Forces 85: 193-216.

Plomin, Robert. 1994. Genetics and Experience: The Interplay between Nature and Nurture. Thousand Oaks, Calif.: Sage Publications.

Plomin, Robert, John C. DeFries, Gerald E. McClearn, and Peter McGuffin. 2005. Behavioral Genetics, 4th ed. New York: Worth Publishers.

Sampson, Robert J., Jeffrey D. Morenoff, and Thomas Gannon-Rowley. 2002. "Assessing 'Neighborhood Effects': Social Processes and New Directions in Research." Annual Review of Sociology 28:443-78.

Schooler, Carmi. 1984. "Psychological Effects of Complex Environments during the Life Span: A Review and Theory." Intelligence 8:259-81.

Schwarz, Norbert, and Fritz Strack. 1999. "Reports of Subjective Well-Being: Judgmental Processes and Their Methodological Implications.” Pp. 61-84 in WellBeing: The Foundations of Hedonic Psychology, edited by Daniel Kahneman, Ed Diener, and Norbert Schwarz. New York: Russell Sage Foundation. 


\section{Happiness and Success}

Smith-Lovin, Lynn. 1995. "The Sociology of Affect and Emotion." Pp. 118-48 in Sociological Perspectives on Social Psychology, edited by Karen S. Cook, Gary A. Fine, and James S. House. Needham Heights, Mass.: Allyn \& Bacon.

Turner, R. Jay. 2003. "The Pursuit of Socially Modifiable Contingencies in Mental Health." Journal of Health and Social Behavior 44:1-17.

Waite, Linda J., and Maggie Gallagher. 2000. The Case for Marriage. New York: Broadway Books. 